\title{
Gas barrier properties of titanium oxynitride films deposited on polyethylene terephthalate substrates by reactive magnetron sputtering
}

\author{
M.-C. Lin ${ }^{\text {a }}$, L.-S. Chang ${ }^{\text {a,* }}$, H.C. Lin ${ }^{b}$ \\ ${ }^{a}$ Department of Materials Science and Engineering, National ChungHsin University, 250, Kuo-Kung Road, 40227 Taichung, Taiwan, ROC \\ ${ }^{\mathrm{b}}$ Department of Materials Science and Engineering, National Taiwan University, 1, Roosevelt Road, Sec. 4, 106 Taipei, Taiwan, ROC \\ Received 22 August 2007; received in revised form 23 November 2007; accepted 23 November 2007
}

Available online 15 December 2007

\begin{abstract}
Titanium oxynitride $\left(\mathrm{TiN}_{x} \mathrm{O}_{y}\right.$ ) films were deposited on polyethylene terephthalate (PET) substrates by means of a reactive radio frequency (RF) magnetron sputtering system in which the power density and substrate bias were the varied parameters. Experimental results show that the deposited $\mathrm{TiN}_{x} \mathrm{O}_{y}$ films exhibited an amorphous or a columnar structure with fine crystalline dependent on power density. The deposition rate increases significantly in conjunction as the power density increases from $2 \mathrm{~W} / \mathrm{cm}^{2}$ to $7 \mathrm{~W} / \mathrm{cm}^{2}$. The maximum deposition rate occurs, as the substrate bias is $-40 \mathrm{~V}$ at a certain power densities chosen in this study. The film's roughness slightly decreases with increasing substrate bias. The $\mathrm{TiN}_{x} \mathrm{O}_{y}$ films deposited at power densities above $4 \mathrm{~W} / \mathrm{cm}^{2}$ show a steady Ti:N:O ratio of about 1:1:0.8. The water vapor and oxygen transmission rates of the $\mathrm{TiN}_{x} \mathrm{O}_{y}$ films reach values as low as $0.98 \mathrm{~g} / \mathrm{m}^{2}$-day-atm and $0.60 \mathrm{~cm}^{3} / \mathrm{m}^{2}$-day-atm which are about 6 and 47 times lower than those of the uncoated PET substrate, respectively. These transmission rates are comparable to those of DLC, carbon-based and $\mathrm{Al}_{2} \mathrm{O}_{3}$ barrier films. Therefore, $\mathrm{TiN}_{x} \mathrm{O}_{y}$ films are potential candidates to be used as a gas permeation barrier for PET substrate.
\end{abstract}

(C) 2007 Elsevier B.V. All rights reserved.

Keywords: Titanium oxynitride; Sputtering; Polyethylene terephthalate (PET); Gas permeation

\section{Introduction}

The increased demand in portable devices, for example, the flexible displays and thin film batteries used in note book computers, mobile phones and various electronic instruments, has led to a great deal of work pertaining to the development of suitable substrate materials. These substrate materials are required to possess certain properties, such as portability, durability, flexibility and optical transparency. To meet these requirements, polymers are considered to be the most appropriate material. Nevertheless, most polymer substrates have some drawbacks. One of the most critical properties of polymer substrates which need to be addressed in order to achieve successful operations is their insufficient resistance to gas permeation.

The deposition of diamond-like carbon (DLC) [1-4], carbon-based [5,6] and metal oxide films [7-9] have been

\footnotetext{
* Corresponding author. Tel.: +886 42284 0500/406; fax: +886 422852433. E-mail address: 1schang@dragon.nchu.edu.tw (L.S. Chang).
}

considered to be a promising technique to improve the properties of polymer substrates used in portable devices by enhancing their resistance to abrasive wear, gas permeation, chemical attack, etc. These DLC, carbon-based and metal oxide films can be successfully deposited by magnetically enhanced chemical vapor deposition, plasma-source ion implantation, RF low-pressure glow discharge, magnetron sputtering and microwave techniques. An alternative coating materials class that may merit consideration are transition-metal oxynitrides $\left(\mathrm{TMeN}_{x} \mathrm{O}_{y}\right)$, which, due to their colorific and optical properties, chemical stability and good adhesion to polymers, have previously been widely employed as a wear resistant, antireflective, decorative and/or diffusion barrier coating for polymer components [10-15]. $\operatorname{TiN}_{x} \mathrm{O}_{y}$ films are representative transition-metal oxynitrides and can be deposited onto substrates by various coating techniques, which include magnetron sputtering [10,11], ion assisted deposition [14], and evaporation [15]. Magnetron sputtering is considered to be more advantageous among these different deposition techniques due to its low processing temperature, dense deposited film, moderate set up cost and high stability in control. 
Polyethylene terepthalate (PET) is one of the most promising polymers being used as flexible substrate due to its excellent optical transparency, chemical stability, high durability and low cost. However, to the author's knowledge, no related paper which investigated the deposition of $\mathrm{TiN}_{x} \mathrm{O}_{y}$ films on PET substrates has been reported. In this study, the $\operatorname{TiN}_{x} \mathrm{O}_{y}$ films were deposited on PET substrates by RF reactive magnetron sputtering. The influences of power density and applied substrate bias on the deposition rate, gas permeation rate, microstructure and composition of the $\operatorname{TiN}_{x} \mathrm{O}_{y}$ films were investigated.

\section{Experimental details}

$\mathrm{TiN}_{x} \mathrm{O}_{y}$ films were deposited by means of a reactive magnetron sputtering system (made by Junsun Corporation, Taiwan). A $5 \mathrm{~cm}$ diameter, $99.999 \%$ pure titanium target was used. The PET substrate, a $\mathrm{C}_{10}-\mathrm{H}_{8}-\mathrm{O}_{4}$ compound with 3-6\% humidity (product no: BD11, Nan-Yan Corporation, Taiwan) had a thickness of $100 \mu \mathrm{m}$. The substrate to target distance was kept at $15 \mathrm{~cm}$ and the holder was rotated at a speed of $10 \mathrm{rpm}$ to improve the film homogeneity. Argon was used as the sputter gas and nitrogen as the reactive gas during sputtering. Depositions were carried out in pure $\mathrm{Ar}$ and $\mathrm{Ar} / \mathrm{N}_{2}$ mixtures. Meanwhile, oxygen atoms existing residually in chamber or coming from the PET substrate would contribute to form the $\mathrm{TiN}_{x} \mathrm{O}_{y}$ films during deposition. The sputtering parameters used in this study are listed in Table 1, in which the power density and dc substrate bias varied while the other parameters were fixed. To clean the substrate surface prior to the deposition and improve film's adhesion, the PET surface was plasma pretreated in a sputtering chamber for $10 \mathrm{~min}$ with a direct current (dc) bias of $-300 \mathrm{~V}$, which is generated by an MP- 1 advanced converter magnetron power supply. The pre-treatment was carried out by using Ar gas with a pressure of $1.8 \mathrm{~Pa}$. The same power supply is used for both pre-treatment of substrate and sputtering process, although their amounts of dc bias were different. The dc bias is applied between the stainless holder and stainless chamber wall. Although the electrical conductivity of the $\operatorname{TiN}_{x} \mathrm{O}_{y}$ film is low, the dc bias between the PET substrate and stainless chamber wall can exhibit sufficient effect on the film deposition.

The water vapor and oxygen transmission rates of uncoated and $\operatorname{TiN}_{x} \mathrm{O}_{y}$ coated PET were measured by a Permatran-w 3/61 and an Ox-Tran 2/61model system (made by MOCON Instrument), respectively. The sample area was

Table 1

The sputtering parameters used in this study

\begin{tabular}{ll}
\hline Target & Ti target $(99.999 \%$ purity $)$ with diameter of $5 \mathrm{~cm}$ \\
Substrate & PET \\
Power density & $2 \mathrm{~W} / \mathrm{cm}^{2}, 4 \mathrm{~W} / \mathrm{cm}^{2}, 6 \mathrm{~W} / \mathrm{cm}^{2}, 7 \mathrm{~W} / \mathrm{cm}^{2}$ \\
dc substrate bias & $0 \mathrm{~V},-20 \mathrm{~V},-40 \mathrm{~V},-60 \mathrm{~V}$ \\
Gas flow ratio & $\mathrm{Ar}: \mathrm{N}_{2}=3: 2$ \\
Base pressure & $1.33 \times 10^{-3} \mathrm{~Pa}$ \\
Working pressure & $1.33 \times 10^{-1} \mathrm{~Pa}$ \\
Deposition time & $60 \mathrm{~min}$ \\
\hline
\end{tabular}

$4.5 \mathrm{~cm} \times 4.5 \mathrm{~cm}$. Both transmission rate measurements were carried out at atmospheric pressure and $40{ }^{\circ} \mathrm{C}$, and under relative humidity of $100 \%$ and $0 \%$, respectively. A multi-function scanning probe microscope (SPM, NS4 D3100CL Digital Instrument) was used to measure the film's roughness. A Si tip with a radius of $10 \mathrm{~nm}$ was used for this analysis. The scanned sample area was $1 \mu \mathrm{m}^{2}$ and the scanning speed was $1 \mathrm{~Hz}$.

The field-emission scanning electron microscope (FESEM, JSM-6700F, JEOL) for studying the coating morphology and microstructure was operated at $1 \mathrm{keV}$ accelerating voltage. The $\mathrm{TiN}_{x} \mathrm{O}_{y}$ surface was coated with a thin platinum layer for SEM observation to prevent charging during FESEM analysis. The crystal structures and chemical compositions of deposited $\mathrm{TiN}_{x} \mathrm{O}_{y}$ films were analyzed by means of a high-resolution transmission electron microscope (HRTEM, JEOL-3010, operated at $200 \mathrm{keV}$ ) and X-ray photoelectron spectroscopy (XPS, Theta Probe, VG), respectively. The XPS spectra were obtained using $\mathrm{Al} \mathrm{K} \alpha \mathrm{X}$-rays operated at $15 \mathrm{kV}$ and $400 \mathrm{~W}$. The $\mathrm{Ti}, \mathrm{N}$ and $\mathrm{O}$ concentrations in films were quantified from the areas under the Ti 2p, $\mathrm{N}$ 1s and $\mathrm{O} 1 \mathrm{~s}$ characteristic signals in the photoelectron spectrum, after carrying out the Shirley background subtraction. Relative sensitivity factors provided by the manufacturer were employed. The sampling size and surface etching time were $1 \mathrm{~cm}^{2}$ and $30 \mathrm{~s}$, respectively. The pressure in the analysis chamber was $8 \times 10^{-8} \mathrm{~Pa}$. The thicknesses of the $\mathrm{TiN}_{x} \mathrm{O}_{y}$ films deposited on pure silicon substrates placed alongside the PET substrates were measured by means of an $\alpha$ step profiler (Dektak ${ }^{3}$ ST, Veeco).

\section{Results and discussion}

\subsection{Chemical composition and microstructure}

Fig. 1 shows the XPS spectra of $\operatorname{TiN}_{x} \mathrm{O}_{y}$ films deposited on PET substrates at various power densities and with a fixed substrate bias of $-40 \mathrm{~V}$. The deposited films were cleaned before XPS analysis to prevent them from contamination by adventitious oxygen. The analysis of XPS spectra in Fig. 1 indicates that $\mathrm{Ti}, \mathrm{N}$ and $\mathrm{O}$ elements coexist in the deposited $\mathrm{TiN}_{x} \mathrm{O}_{y}$ films. The appearance of $\mathrm{O}$ element is consistent with the reported studies on titanium oxynitride and aluminum oxynitride films by Guillot et al. [16] and Dreer et al. [17]. Their films were also deposited in a sputter chamber with very little or even no oxygen content. This indicates that at a base pressure of $5 \times 10^{-6} \mathrm{~Pa}$ or even below, there is enough oxygen present to partake in the reaction with $\mathrm{Ti}$ and $\mathrm{N}$ atoms to form the $\mathrm{TiN}_{x} \mathrm{O}_{y}$ films. In this work, the $\mathrm{H}_{2} \mathrm{O}$ molecules which adhere on the surface or exist in the interior of PET substrates [18], and the residual $\mathrm{O}_{2}$ impurity in the sputter chamber, are expected to provide the $\mathrm{O}$ atoms during the deposition of $\operatorname{TiN}_{x} \mathrm{O}_{y}$ films.

Fig. 2(a-c) shows the XPS Ti $2 \mathrm{p}$ lines of $\mathrm{TiN}_{x} \mathrm{O}_{y}$ films deposited onto PET at various power densities with a fixed substrate bias of $-40 \mathrm{~V}$. As shown in Fig. 2(a), there occurs a predominant $\mathrm{Ti}-\mathrm{O}_{2}$ bonding for the film deposited at a power density of $2 \mathrm{~W} / \mathrm{cm}^{2}$. By increasing power density to $4 \mathrm{~W} / \mathrm{cm}^{2}$ or $7 \mathrm{~W} / \mathrm{cm}^{2}$, there occurs both $\mathrm{Ti}-\mathrm{N}$ and $\mathrm{Ti}-\mathrm{O}_{2}$ bonding in the deposited film, as shown in Fig. 2(b-c). This feature can be 

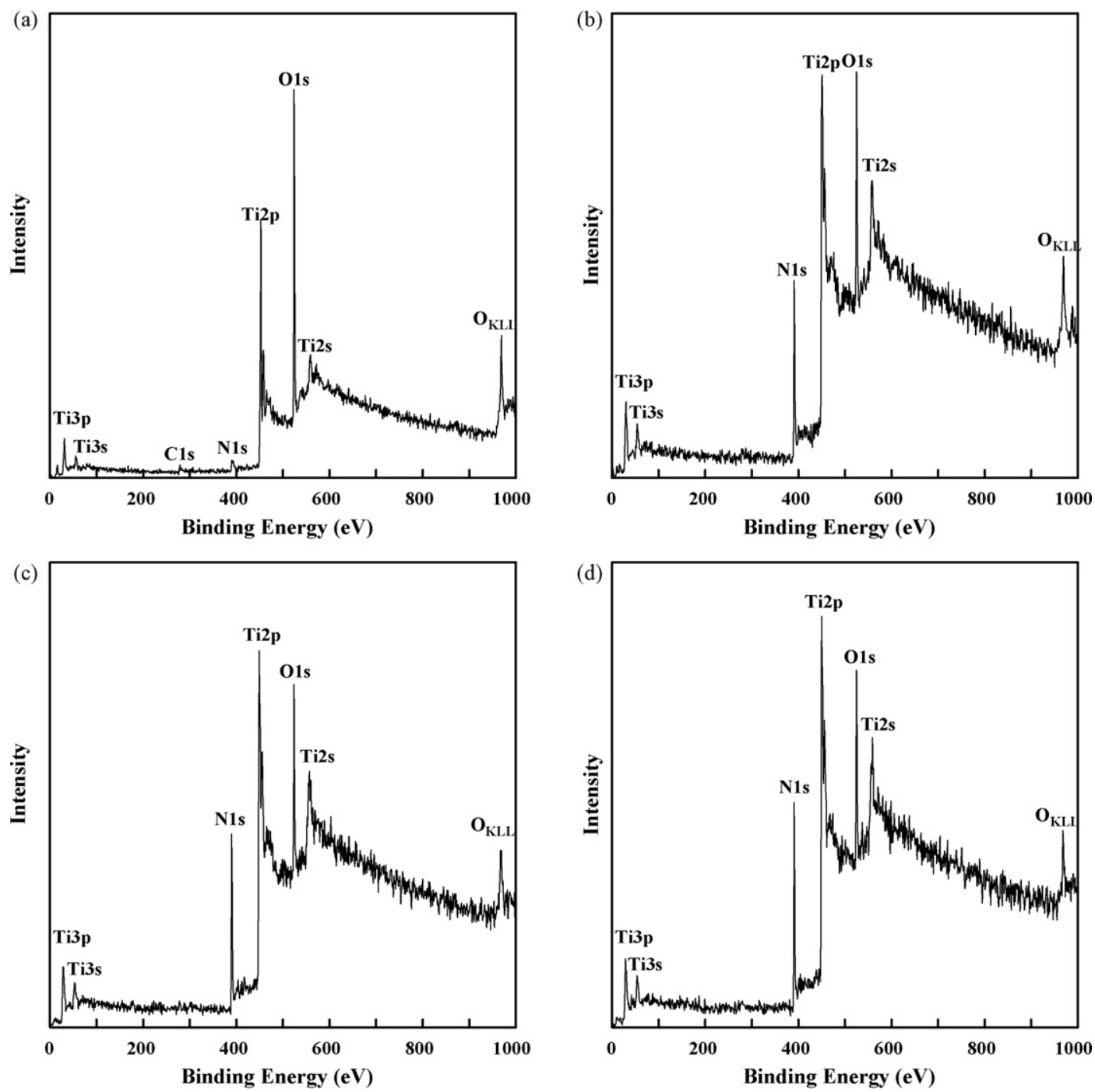

Fig. 1. XPS spectra of $\operatorname{TiN}_{x} \mathrm{O}_{y}$ films deposited on PET with a fixed substrate bias of $-40 \mathrm{~V}$ at various power densities. (a) $2 \mathrm{~W} / \mathrm{cm}^{2},(\mathrm{~b}) 4 \mathrm{~W} / \mathrm{cm}^{2},(\mathrm{c}) 6 \mathrm{~W} / \mathrm{cm}^{2}$, (d) $7 \mathrm{~W} / \mathrm{cm}^{2}$.

explained as below. At a low power density of $2 \mathrm{~W} / \mathrm{cm}^{2}$, less quantity of Ti atoms are sputtered from the Ti target, and some $\mathrm{Ti}$ ions are created after sputtering due to charge exchange. These Ti atoms (ions) will first react with $\mathrm{O}$ due to their strong affinity. Therefore, the deposited film is mainly comprised of Ti and $\mathrm{O}$ elements. With increasing power density, more Ti atoms are sputtered from Ti target and more Ti ions are created due to charge exchange. There is more opportunity to form the Ti-N bonding besides of the $\mathrm{Ti}-\mathrm{O}_{2}$ bonding. Therefore, the XPS spectra intensities of $\mathrm{Ti}$ and $\mathrm{N}$ elements maintain steady values at higher power densities, as shown in Fig. 1(b-d) and Fig. 2(bc). Based on the quantitative analysis of XPS, the compositions of $\mathrm{TiN}_{x} \mathrm{O}_{y}$ films deposited at various power densities are presented in Fig. 3. As can be seen in Fig. 3, the $\operatorname{TiN}_{x} \mathrm{O}_{y}$ films deposited at power densities above $4 \mathrm{~W} / \mathrm{cm}^{2}$ show a steady Ti:N:O ratio of about 1:1:0.8.

Fig. 4(a-c) shows the HR-TEM cross-sectional images and diffraction patterns of $\operatorname{TiN}_{x} \mathrm{O}_{y}$ films deposited onto PET at various power densities with a fixed substrate bias of $-40 \mathrm{~V}$. In Fig. 4(a), the $\mathrm{TiN}_{x} \mathrm{O}_{y}$ film deposited at power densities of $2 \mathrm{~W} /$ $\mathrm{cm}^{2}$ exhibits an amorphous structure. Increasing the power density to higher than $4 \mathrm{~W} / \mathrm{cm}^{2}$, the $\operatorname{TiN}_{x} \mathrm{O}_{y}$ film exhibits a columnar structure with fine crystalline, as shown in Fig. 4(bc). The occurrence of columnar structure with fine crystalline in $\mathrm{TiN}_{x} \mathrm{O}_{y}$ films may be ascribed to the rising of substrate temperature during the deposition process. The bombardment of the sputtered atoms (ions) will raise the substrate temperature during the deposition of $\operatorname{TiN}_{x} \mathrm{O}_{y}$ films. At a higher power density, more sputtered atoms (ions) are bombarded onto the PET substrate and the substrate temperature is increased to a higher one. In the present study, the substrate temperature during deposition can reach about $80^{\circ} \mathrm{C}$ at a power density of $7 \mathrm{~W} / \mathrm{cm}^{2}$. This rising of substrate temperature will exhibit sufficient driving force for columnar structure to with fine crystalline. As illustrated clearly in Fig. 4(b) and (c), the higher the power density, the more obvious the columnar structure with fine crystalline. Besides, it is worthy to mention that the indistinct trace surrounding the surface of these columnar structures in Fig. 4(b-c) is only a false image introduced during the preparation of TEM specimens. 

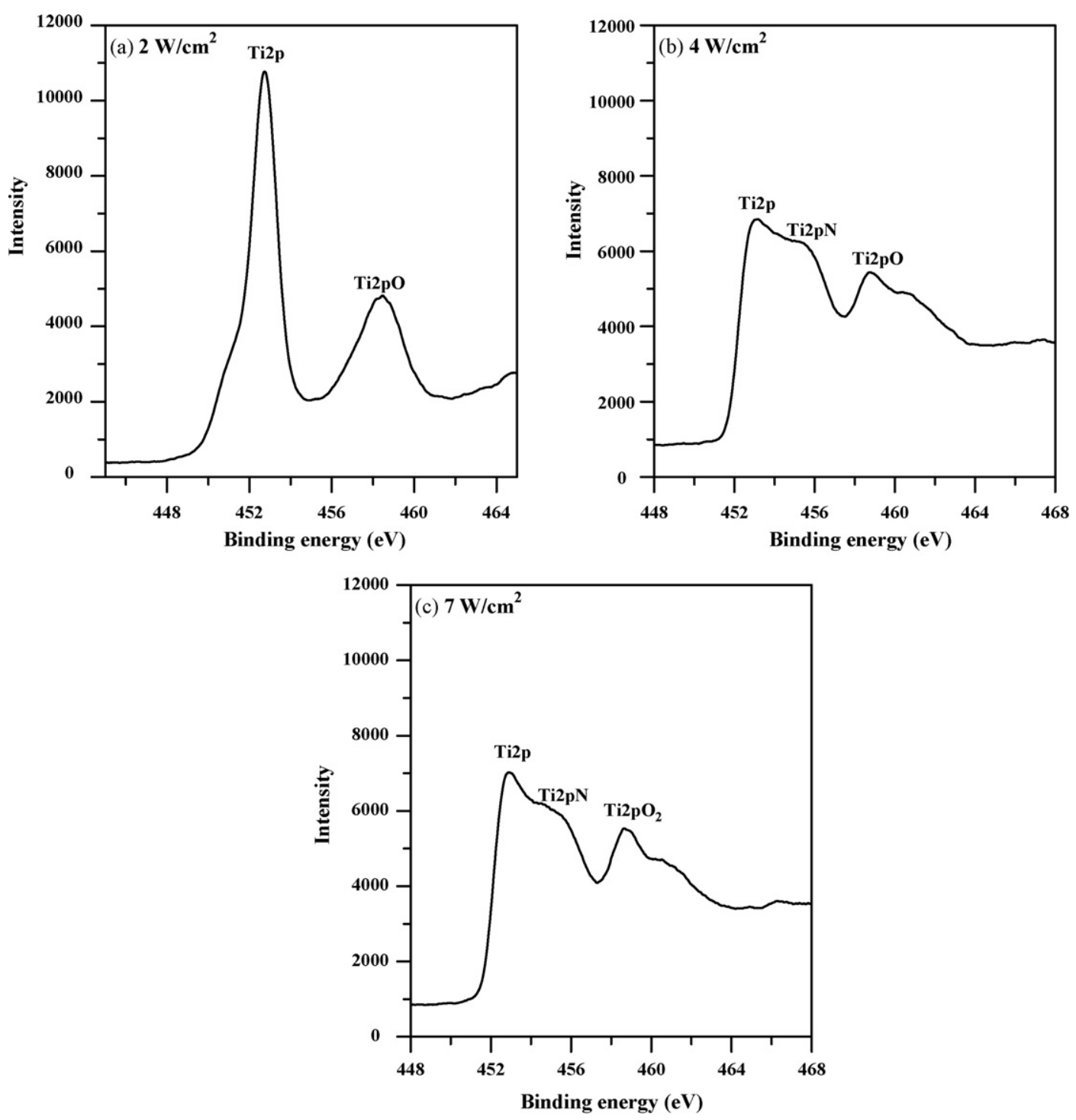

Fig. 2. The XPS Ti $2 p$ lines of $\operatorname{TiN}_{x} \mathrm{O}_{y}$ films deposited onto PET at various power densities and with a fixed substrate bias of $-40 \mathrm{~V}$.

\subsection{Deposition rate}

Fig. 5 shows the deposition rates of $\operatorname{TiN}_{x} \mathrm{O}_{y}$ films deposited at various power densities and substrate biases. It is found that the deposition rate increases significantly with increasing power density. The deposition rate increases 4-9 times, depending on the power density in the range of $2-7 \mathrm{~W} / \mathrm{cm}^{2}$. This phenomenon can be explained as follows. At higher power density, more $\mathrm{Ar}^{+}$and $\mathrm{N}_{2}{ }^{+}$ions are generated to impact the titanium target and more $\mathrm{Ti}$ atoms (ions) are sputtered out and react with $\mathrm{N}$ and $\mathrm{O}$ atoms in the plasma to form $\operatorname{TiN}_{x} \mathrm{O}_{y}$ and deposit onto the PET substrate. Hence, the deposition rate of $\mathrm{TiN}_{x} \mathrm{O}_{y}$ film increases with increasing power density.

One can also find, in Fig. 5, that the deposition rate increases slightly from $0 \mathrm{~V}$ to $-20 \mathrm{~V}$ bias, reaches a maximum at $-40 \mathrm{~V}$ bias, and then decreases at $-60 \mathrm{~V}$ bias. Actually, proper supply of substrate bias (such as $-20 \mathrm{~V}$ to $-40 \mathrm{~V}$ ) will raise the negative potential between the ground and substrate. Ti ions are more guided onto the substrate surface due to this negative potential. Besides, the moving direction of other species (Ti and
$\mathrm{N}$ atoms) will also be more confined to around the substrate due to the collision with these guided Ti ions. All these effects will increase the adhesion of deposited species onto the substrate, and hence increase the film's deposition rate. [19,20]. However, an over-high substrate bias (such as $-60 \mathrm{~V}$ ) will produce a significant drop of electrical potential in the plasma. This will make the species (atoms or ions) have over-high impact energy and induce re-sputtering, and hence the deposition rate of $\mathrm{TiN}_{x} \mathrm{O}_{y}$ film decreases significantly. It is worthy to mention that the maximum deposition rate of $\operatorname{TiN}_{x} \mathrm{O}_{y}$ films, shown in Fig. 5, is only about $1.2 \mathrm{~nm} / \mathrm{min}$, which is much lower than those of $\operatorname{DLC}(750 \mathrm{~nm} / \mathrm{min})$ [1], carbon-based $(21 \mathrm{~nm} / \mathrm{min})$ and $\mathrm{Al}_{2} \mathrm{O}_{3}$ $(51 \mathrm{~nm} / \mathrm{min})$ films [5,7].

\subsection{Surface morphology and roughness}

Fig. 6(a-d) shows the FESEM micrographs of $\mathrm{TiN}_{x} \mathrm{O}_{y}$ films deposited onto PET at various power densities and without substrate bias. As shown in Fig. 6(a), many small pinholes appear in the $\operatorname{TiN}_{x} \mathrm{O}_{y}$ film prepared at a power density of $2 \mathrm{~W} /$ 


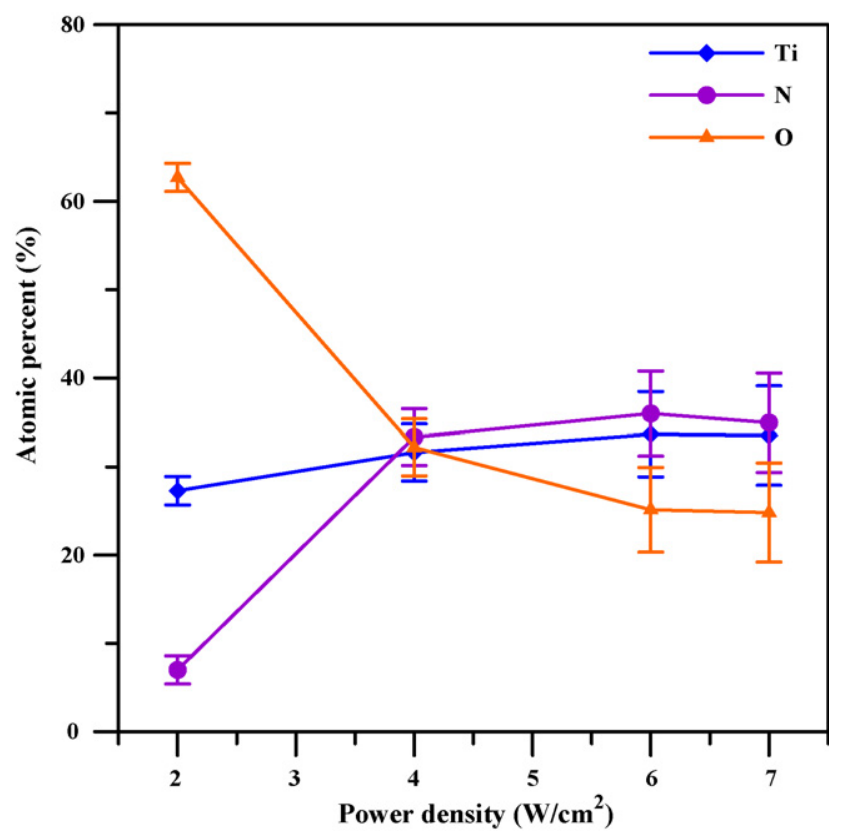

Fig. 3. Chemical compositions of $\mathrm{TiN}_{x} \mathrm{O}_{y}$ films deposited onto PET at various power densities and with a fixed substrate bias of $-40 \mathrm{~V}$.

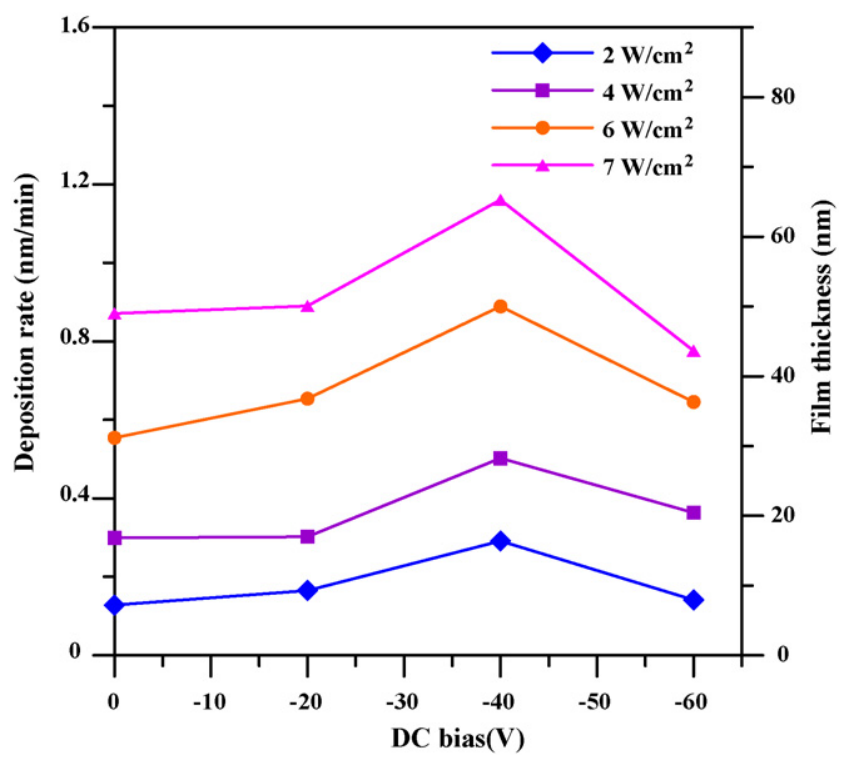

Fig. 5. Deposition rates of $\operatorname{TiN}_{x} \mathrm{O}_{y}$ films on PET in dependence of the substrate bias at various power densities (film thickness $=$ deposition rate $\times 60$ ).
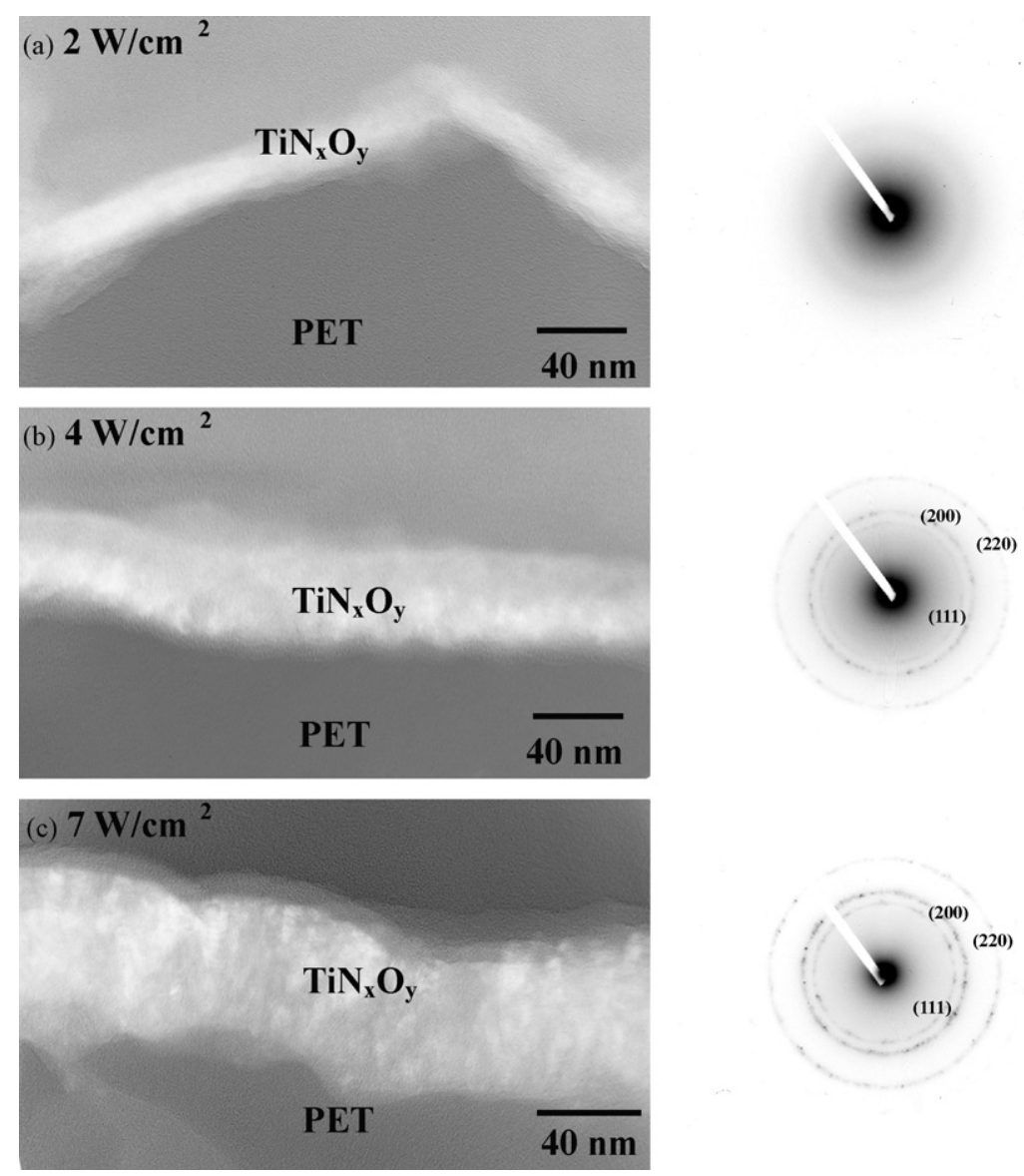

(200) (220)

(111) 

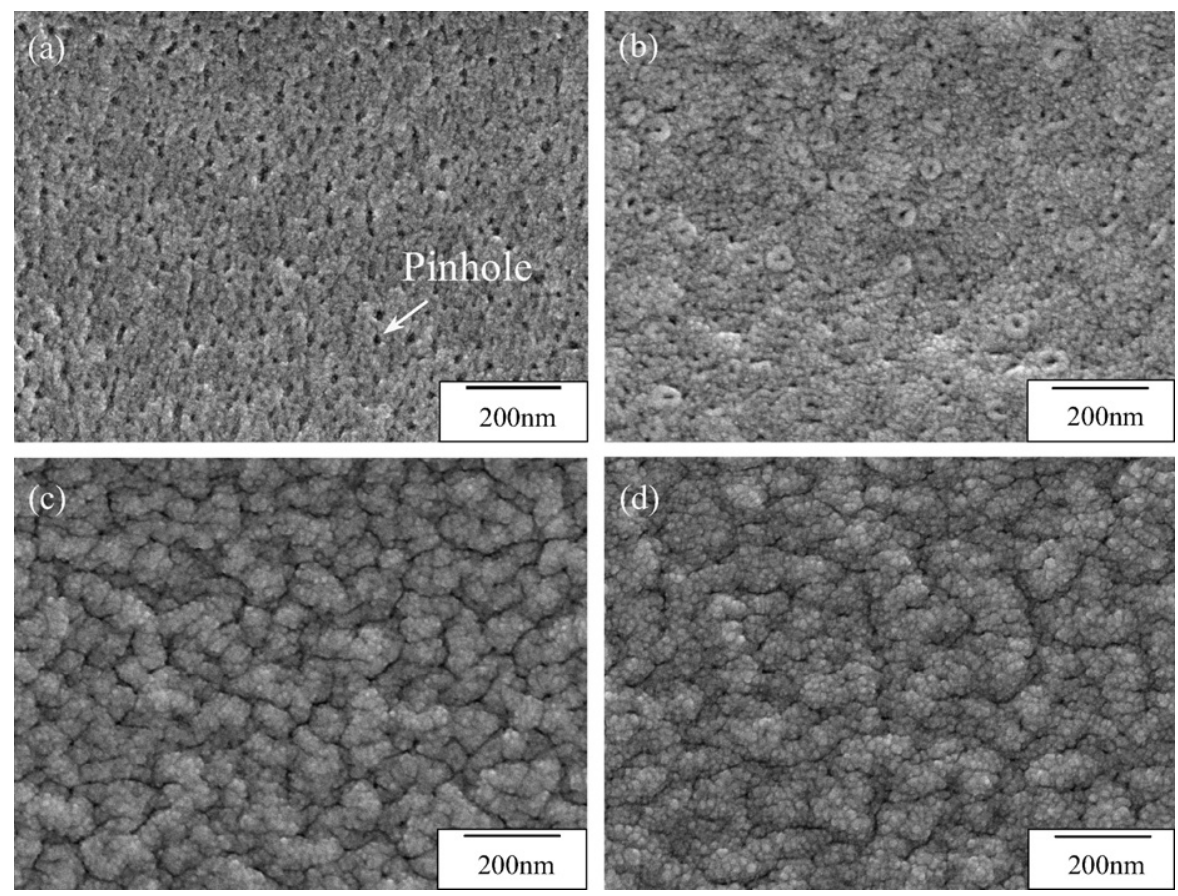

Fig. 6. FESEM micrographs of $\operatorname{TiN}_{x} \mathrm{O}_{y}$ films deposited on PET at various power densities without substrate bias. (a) $2 \mathrm{~W} / \mathrm{cm}^{2}$, (b) $4 \mathrm{~W} / \mathrm{cm}^{2}$, (c) $6 \mathrm{~W} / \mathrm{cm}^{2}$, (d) $7 \mathrm{~W} /$ $\mathrm{cm}^{2}$.

$\mathrm{cm}^{2}$. This may come from the fact that the sputter species (atoms or ions) have smaller mobility at a lower power density of $2 \mathrm{~W} / \mathrm{cm}^{2}$, and hence the deposited $\operatorname{TiN}_{x} \mathrm{O}_{y}$ film grows with a lot of small pinholes. By increasing power density to $4 \mathrm{~W} / \mathrm{cm}^{2}$, the quantity of pinhole decreases, as shown in Fig. 6(b). If power density is higher than $6 \mathrm{~W} / \mathrm{cm}^{2}$, as shown in Fig. $6(\mathrm{c}-\mathrm{d})$, no pinholes are observed on the $\operatorname{TiN}_{x} \mathrm{O}_{y}$ films. This indicates that the sputter species (atoms or ions) will have enough mobility to deposit a dense $\operatorname{TiN}_{x} \mathrm{O}_{y}$ film without pinholes at power densities higher than $6 \mathrm{~W} / \mathrm{cm}^{2}$.

Fig. 7(a-d) shows the FESEM micrographs of $\operatorname{TiN}_{x} \mathrm{O}_{y}$ films deposited on PET with various substrate biases and at a fixed power density of $7 \mathrm{~W} / \mathrm{cm}^{2}$. One can find that most $\operatorname{TiN}_{x} \mathrm{O}_{y}$ films (Fig. 7(a-c)) exhibit a cluster-type surface morphology dotted with tiny particles. Differing from that, the $\operatorname{TiN}_{x} \mathrm{O}_{y}$ film deposited with $-60 \mathrm{~V}$ bias (Fig. 7(d)) exhibits a surface
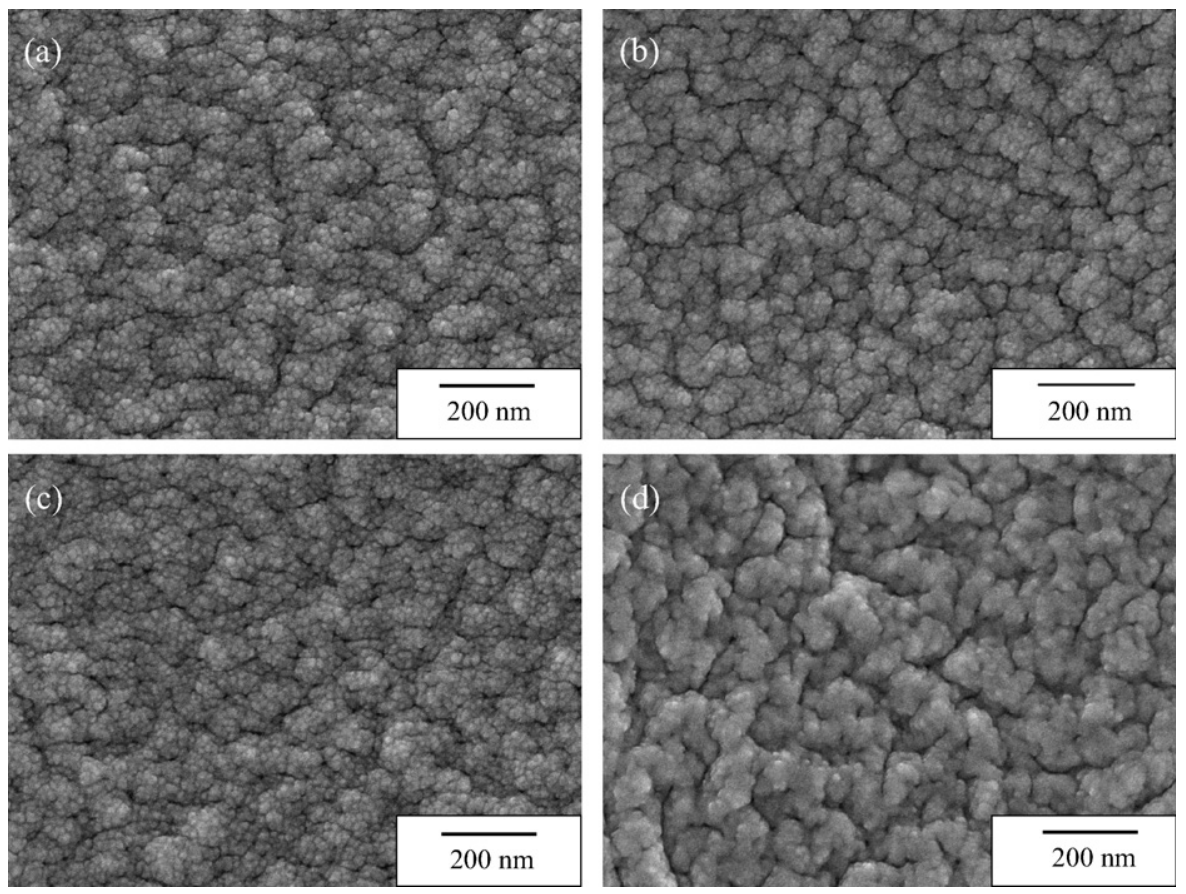

Fig. 7. FESEM micrographs of $\operatorname{TiN}_{x} \mathrm{O}_{y}$ films deposited on PET at a power density of $7 \mathrm{~W} / \mathrm{cm}^{2}$ with various substrate biases. (a) $0 \mathrm{~V}$ (b) $-20 \mathrm{~V}$ (c) $-40 \mathrm{~V}$ (d) $-60 \mathrm{~V}$. 


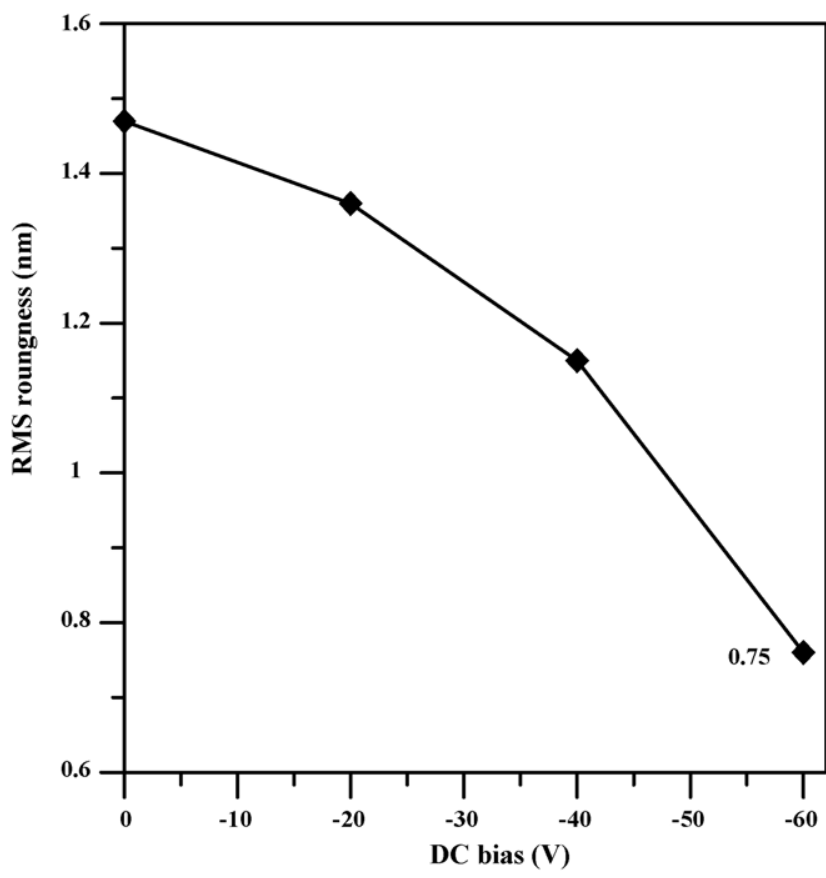

Fig. 8. RMS roughness of $\operatorname{TiN}_{x} \mathrm{O}_{y}$ films deposited on PET in dependence of the substrate bias. The power density was $7 \mathrm{~W} / \mathrm{cm}^{2}$.

morphology without those closely dotted tiny particles. This feature is ascribed to the fact that the species (atoms or ions) in the plasma with $-60 \mathrm{~V}$ bias have over-high impact energy to bombard the surface of $\mathrm{TiN}_{x} \mathrm{O}_{y}$ films. This intense bombardment may impinge away those tiny particles on $\mathrm{TiN}_{x} \mathrm{O}_{y}$ films, although some of those tiny particles may be incorporated in the film during the continuous deposition process. This phenomenon is consistent with the result of the re-sputtering effect discussed in Section 3.2.

The values of root-mean-square (RMS) roughness of $\operatorname{TiN}_{x} \mathrm{O}_{y}$ films deposited on PET with various substrate biases, measured by using the scanning probe microscope, are presented in Fig. 8. The film's surface roughness decreases with increasing

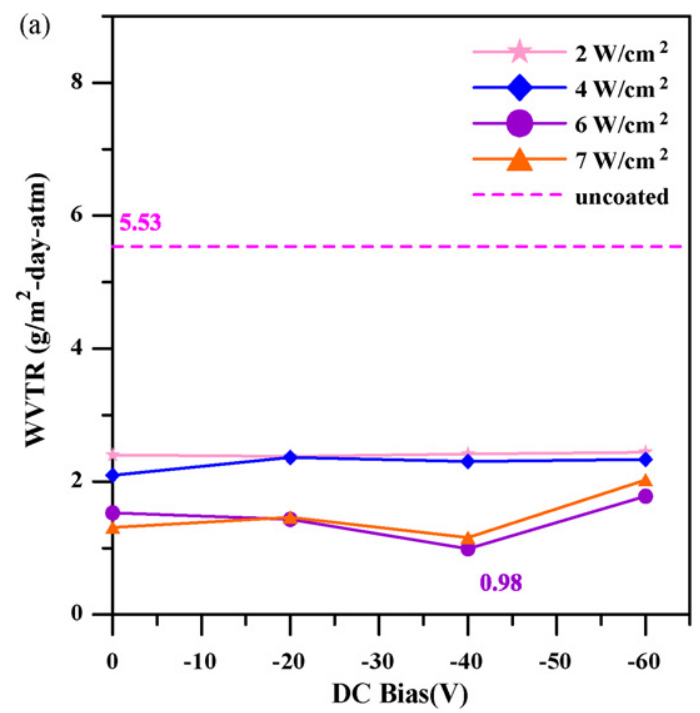

substrate bias. The kinetic energy of depositing atoms is increased at higher substrate bias. These depositing atoms with higher kinetic energy will easily move into the space between clusters and hence the $\mathrm{TiN}_{x} \mathrm{O}_{y}$ films can exhibit smoother surface morphologies at higher substrate bias. The re-sputtering effect at higher substrate bias also smoothens the film surface as shown in Fig. 7(d).

\subsection{Gas permeation}

The water vapor transmission rate (WVTR) and oxygen transmission rate (OTR) of $\mathrm{TiN}_{x} \mathrm{O}_{y}$ films coated PET in dependence on power densities and substrate biases are plotted in Fig. 9(a) and (b), respectively. The WVTR and OTR of uncoated PET are $5.53 \mathrm{~g} / \mathrm{m}^{2}$-atm-day and $28.09 \mathrm{~cm}^{3} / \mathrm{m}^{2}$-atmday, respectively. It can be clearly seen in Fig. 9(a-b) that the WVTR and OTR of the PET substrates reduce significantly after the deposition of $\operatorname{TiN}_{x} \mathrm{O}_{y}$ films. From these two figures, it can be concluded that both the film's thickness and quality, resulting from the different power densities and substrate biases, have important effects on the film's resistance against gas permeation.

As already mentioned, the deposition rate of $\operatorname{TiN}_{x} \mathrm{O}_{y}$ film increases with increasing power density, and hence the film thickness and consequent resistance against permeation of water vapor and oxygen also increase. It has also been shown in Fig. 5 that, the deposition rate reaches a maximum at $-40 \mathrm{~V}$ bias and then decreases due to re-sputtering at $-60 \mathrm{~V}$ bias. This feature can explain why the WVTR and OTR reduce as the substrate bias changes from $0 \mathrm{~V}$ to $-40 \mathrm{~V}$, and then rise as the bias ranges from $-40 \mathrm{~V}$ to $-60 \mathrm{~V}$, as shown in Fig. 9. All these results exhibit that a thicker $\operatorname{TiN}_{x} \mathrm{O}_{y}$ film will be a better gas barrier [21,22]. In Fig. 9, the OTR of $\mathrm{TiN}_{x} \mathrm{O}_{y}$ films deposited at power density of $2 \mathrm{~W} / \mathrm{cm}^{2}$ is found to have almost the same value as that of uncoated PET substrate. This phenomenon is understandable and can be explained as below. As shown in Fig. 6(a), $\mathrm{TiN}_{x} \mathrm{O}_{y}$ films deposited at power density of $2 \mathrm{~W} / \mathrm{cm}^{2}$

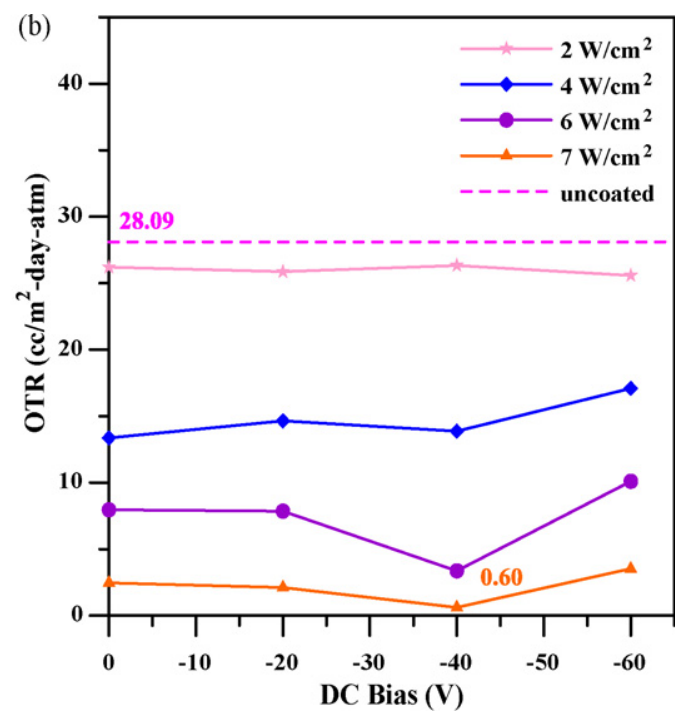

Fig. 9. (a) WVTR and (b) OTR of $\mathrm{TiN}_{x} \mathrm{O}_{y}$ films coated PET in dependence of the substrate biases and power densities. 
have many small pinholes. These small pinholes act as the shortcut for oxygen permeation, and these films have high OTR values. It is worthwhile mentioning that these small pinholes existing in $\mathrm{TiN}_{x} \mathrm{O}_{y}$ films still have an effective resistance to water vapor, so their WVTR still maintains a quite low value (Fig. 9(a)).

As discussed above, properly deposited $\mathrm{TiN}_{x} \mathrm{O}_{y}$ films can significantly improve the barrier properties of PET substrates. In this study, the optimal sputtering parameters in depositing excellent $\mathrm{TiN}_{x} \mathrm{O}_{y}$ films are power density of $7 \mathrm{~W} / \mathrm{cm}^{2}$ and $-40 \mathrm{~V}$ substrate bias. The water vapor and oxygen transmission rates of these optimal $\mathrm{TiN}_{x} \mathrm{O}_{y}$ films reach values as low as $0.98 \mathrm{~g} / \mathrm{m}^{2}$-day-atm and $0.60 \mathrm{~cm}^{3} / \mathrm{m}^{2}$-day-atm, respectively. These values of WVTR and OTR are about 6 and 47 times lower than those of the uncoated PET substrate.

It is valuable to compare briefly the gas permeation resistance of $\mathrm{TiN}_{x} \mathrm{O}_{y}$ films and those currently used DLC, carbon-based and $\mathrm{Al}_{2} \mathrm{O}_{3}$ films. As presented above, the water vapor and oxygen transmission rates of the $\mathrm{TiN}_{x} \mathrm{O}_{y}$ films prepared in this study can reach optimal values of $0.98 \mathrm{~g} / \mathrm{m}^{2}$ day-atm and $0.60 \mathrm{~cm}^{3} / \mathrm{m}^{2}$-day-atm, respectively. In the reported studies, the oxygen transmission rates of DLC and carbon-based films are about $0.4-4.5 \mathrm{~cm}^{3} / \mathrm{m}^{2}$-day-atm [1-4] and $5.7 \mathrm{~cm}^{3} / \mathrm{m}^{2}$-day-atm [6], respectively, and the water transmission rate of $\mathrm{Al}_{2} \mathrm{O}_{3}$ is about $1.12 \mathrm{~g} / \mathrm{m}^{2}$-day-atm [7]. Hence, based on these data, the $\operatorname{TiN}_{x} \mathrm{O}_{y}$ films can exhibit similar or even higher resistance of gas permeation as compared to DLC, carbon-based and $\mathrm{Al}_{2} \mathrm{O}_{3}$ barrier films. Namely, $\mathrm{TiN}_{x} \mathrm{O}_{y}$ films are potential candidates to be used as a gas permeation barrier. Meanwhile, the $\operatorname{TiN}_{x} \mathrm{O}_{y}$ films can have better electric conductivity than $\mathrm{Al}_{2} \mathrm{O}_{3}$ films, higher mechanical property than carbon-based films and their manufacturing cost is lower than that of DLC films.

\section{Conclusions}

$\mathrm{TiN}_{x} \mathrm{O}_{y}$ films have been successfully deposited on PET substrates by means of the RF reactive magnetron sputtering technique. The influences of power density and substrate bias on the film's properties are investigated. The $\mathrm{TiN}_{x} \mathrm{O}_{y}$ film deposited at power density of $2 \mathrm{~W} / \mathrm{cm}^{2}$ exhibits an amorphous structure. With increasing power density to be higher than $4 \mathrm{~W} /$ $\mathrm{cm}^{2}$, the $\mathrm{TiN}_{x} \mathrm{O}_{y}$ film exhibits a columnar structure with fine crystalline. The deposition rate of $\mathrm{TiN}_{x} \mathrm{O}_{y}$ film has an increment of 4-9 times, when the power density rises from $2 \mathrm{~W} / \mathrm{cm}^{2}$ up to $7 \mathrm{~W} / \mathrm{cm}^{2}$. The deposition rate reaches its maximum with the substrate bias of $-40 \mathrm{~V}$ at all power densities chosen in this study. Most $\operatorname{TiN}_{x} \mathrm{O}_{y}$ films exhibit a cluster-type surface morphology with closely dotted tiny particles. Their surface roughness decreases slightly with increasing substrate bias. A lot of small pinholes are observed in $\mathrm{TiN}_{x} \mathrm{O}_{y}$ films deposited at a low power density of $2 \mathrm{~W} / \mathrm{cm}^{2}$. The $\mathrm{TiN}_{x} \mathrm{O}_{y}$ films deposited at power densities above $4 \mathrm{~W} / \mathrm{cm}^{2}$ show a steady $\mathrm{Ti}: \mathrm{N}: \mathrm{O}$ ratio of about 1:1:0.8. The film's resistance against gas permeation increases with increasing film's thickness and quality, resulting from the different power densities and substrate biases. The water vapor and oxygen transmission rates of the $\operatorname{TiN}_{x} \mathrm{O}_{y}$ films reach optimal values as low as $0.98 \mathrm{~g} / \mathrm{m}^{2}$-day-atm and $0.60 \mathrm{~cm}^{3} / \mathrm{m}^{2}$-day-atm and these values are about 6 and 47 times lower than those of the uncoated PET substrate, respectively, while the power density is $7 \mathrm{~W} / \mathrm{cm}^{2}$ and substrate bias is $-40 \mathrm{~V}$. As compared to DLC, carbon-based and $\mathrm{Al}_{2} \mathrm{O}_{3}$ barrier films, the sputtered $\mathrm{TiN}_{x} \mathrm{O}_{y}$ films can exhibit similar or even higher resistance of gas permeation. Besides, the $\operatorname{TiN}_{x} \mathrm{O}_{y}$ films can have better electric conductivity than $\mathrm{Al}_{2} \mathrm{O}_{3}$ films, higher mechanical property than carbon-based films and their manufacturing cost is lower than that of DLC films.

\section{Acknowledgement}

This work was financially supported by the National Science Committee (NSC) of Taiwan/ROC, under the auspices of the Targeted Project (no. NSC93-2216-E-005-024).

\section{References}

[1] K. Inagawa, T. Zeniya, N. Hibino, Surf. Coat. Technol. 169/170 (2003) 344.

[2] S. Yamamoto, H. Kodama, T. Hasebe, A. Shirakura, T. Suzuki, Diamond Relat. Mater. 14 (2005) 1112.

[3] M. Yoshida, S. Watanabe, T. Tanaka, T. Takagi, M. Shinohara, J.W. Lee, Nucl. Instrum. Methods Phys. Res. B 206 (2003) 712.

[4] M. Yoshida, T. Tanaka, S. Watanabe, M. Shinohara, J.W. Lee, T. Takagi, Surf. Coat. Technol. 174/175 (2003) 1033.

[5] S. Watanabe, M. Shinohara, H. Kodama, T. Tanaka, M. Yoshida, T. Takagi, Thin Solid Films 420/421 (2002) 253.

[6] H. Kodama, A. Shinohara, A. Hotta, T. Suzuki, Surf. Coat. Technol. 201 (2006) 913.

[7] B.M. Henry, F. Dinelli, K.-Y. Zhao, C.R.M. Grovenor, O.V. Kolosov, G.A.D. Briggs, A.P. Roberts, R.S. Kumar, R.P. Howson, Thin Solid Films 355/356 (1999) 500.

[8] M. Benmalek, H.M. Dunlop, Surf. Coat. Technol. 76/77 (1995) 821.

[9] A.S. da Silva Sobrinho, G. Czeremuszkin, M. Latreche, M.R. Wertheimer, J. Vac. Sci. Technol. A 18 (2000) 149.

[10] F. Vaz, P. Cerqueira, L. Rebouta, S.M.C. Nascimento, E. Alves, Ph. Goudeau, J.P. Riviere, K. Psichow, J. de Rijk, Thin Solid Films 447/ 448 (2004) 449.

[11] M.H. Kazemeini, A.A. Berezin, N. Fukuhara, Thin Solid Films 372 (2000) 70.

[12] N. Martin, O. Banakh, A.M.E. Santo, S. Springer, R. Sanjines, J. Takadoum, F. Levy, Appl. Surf. Sci. 185 (2001) 123.

[13] F. Vaz, P. Cerqueira, L. Rebouta, S.M.C. Nascimento, E. Alves, Ph. Goudeau, J.P. Riviere, Surf. Coat. Technol. 174/175 (2003) 197.

[14] A. Bittar, D. Cochrane, S. Caughley, I. Vickeridge, J. Vac. Sci. Technol. A15 (2) (1997) 223.

[15] M. Lazaror, P. Raths, H. Metager, W. Spirkl, J. Appl. Phys. 77 (5) (1995) 2133.

[16] J. Guillot, A. Jouaiti, L. Imhoff, B. Domenichini, O. Heintz, S. Zerkout, A. Mosser, S. Bourgeois, Surf. Interface Anal. 34 (2002) 577.

[17] S. Dreer, R. Krismer, P. Willhartitz, G. Friedbacher, Thin Solid Films 354 (1999) 43.

[18] M. Neuhäuser, S. Bärwulf, H. Hilgers, E. Lugscheider, M. Riester, Surf. Coat. Technol. 116-119 (1999) 981.

[19] K. Koski, J. Hölsä, P. Juliet, Surf. Coat. Technol. 120/121 (1999) 303.

[20] S. Ben Amor, B. Rogier, G. Baud, M. Jacquet, M. Nardin, Mater. Sci. Eng. B57 (1998) 28.

[21] R.S. Kumar, M. Auch, E. Ou, G. Ewald, C.S. Jin, Thin Solid Films 417 (2002) 120-126.

[22] A.P. Roberts, B.M. Henry, A.P. Sutton, C.R.M. Grovenor, G.A.D. Briggs, T. Miyamoto, M. Kano, Y. Tsukahara, M. Yanaka, J. Membr. Sci. 208 (2002) 75. 